\title{
OPTION OF SOLID POLLUTANTS ABATEMENT IN FLUE GAS PATH
}

Biomass combustion produces gaseous and solid pollution. Solid pollutants are small particles which are getting into the air with smoke and may be harmful to the environment, the human and animal health. Therefore, it is important to decrease their amount in the ambient atmosphere. Particulate matter sources are not only big combustion devices but also small combustion devices which are quite common and widely used. It is necessary to mention that the small boilers are not as monitored as bigger ones. Therefore, they are potentially a large source of pollution. The main objective of this work is to reduce particulate matter concentration produced by small residential combustion appliances by making a change of the geometric parameters in a flue gas path.

Keywords: Pollution from biomass, particulate matter, separation

\section{Introduction}

There is nowadays worldwide high encouragement of taking up of the biomass as a heat and energy source. The renewable energy sources replace fossil fuels in order to reduce the amount of total pollution in atmosphere. The combustion is the most developed and the most frequently applied thermochemical technology of conversion of biomass into the useful energy. The combustion of solid biomass produces less pollution than the combustion of fossil fuels, but there are still some pollutants [1]

The air quality is very important not only for humans, but also for all organisms living on the Earth and for general function of all ecosystems. Previous observations show that there are problems with a higher particulate matter concentration in many countries [2]. As a consequence of this fact, European countries make changes in legislation that regulate the amount of emissions. The monitoring of pollution and stricter emission legislation should help to decrease their amount.

One of the pollutants which extensively effects air quality is particulate matter that is generally coming into the ambient atmosphere from various sources, for instance, traffic, factories and volcanoes. But there is also one potentially big source of particulate matter pollution - small combustion appliances. The domestic heating sources have a big potential because they are numerous and, especially during winter heating season, produce particulate matter pollution. Those uncontrolled combustion appliances (because they are not monitored) contribute to the air pollution on a large scale and it is estimated that those small sources produce from $20 \%$ to $90 \%$ of the total emission of particulate matter in the winter [ 1 and 3].

In many cases small combustion boilers do not have any additional appliances to reduce pollution. There is high probability of incomplete combustion leading to the production of fine particles and hazardous organic compounds in small heat sources. During process of biomass combustion the solid particles are formed and emitted together with smoke into the ambient air. In many European countries the problems with increased amount of the particulate matter persist and, as a consequence, this may cause various diseases [3].

With view to minimize the production of particulate matter emission and improve air quality various ways of their reduction are used. Filters or external separators can be used, but they are costly; sometimes the same price or even more expensive than the heat source itself. Therefore, new solutions which are not so costly and are effective enough to decrease the amount of solid particles are looked for. Such a solution can be a change of a construction and design parameters of a heat source, especially change of a design parameter in the combustion chamber and flue gas path.

\subsection{Particulate Matter}

Many of the scientific studies deal with particulate matter pollution and its influence on human being. Exposure to such particles can affect both lungs and heart, especially fine particles - containing microscopic solids that are so small that they can get deep into the lungs (Fig. 1) and cause serious health problems [4, 5 and 6].

Particulate matters may generally increase the risk of respiratory and cardiovascular diseases, higher mortality, more allergies, aggravated asthma, nonfatal heart attacks, irregular heartbeat, decreased lung function, and increased respiratory symptoms, such as irritation of the airways, coughing or difficulty

\footnotetext{
* Katarina Sulovcova, Jozef Jandacka

Department of Power Engineering, Faculty of Mechanical Engineering, University of Zilina, Slovakia, E-mail: katarina.sulovcova@fstroj.uniza.sk
} 
with breathing etc. [4, 5 and 6]. Mortality associated with air pollution is about $15-20 \%$ higher in cities with high levels of pollution compared to relatively cleaner cities. In the European Union, average life expectancy is estimated to be 8.6 months lower due to exposure to $\mathrm{PM}_{2.5}$ resulting from human activities [7].

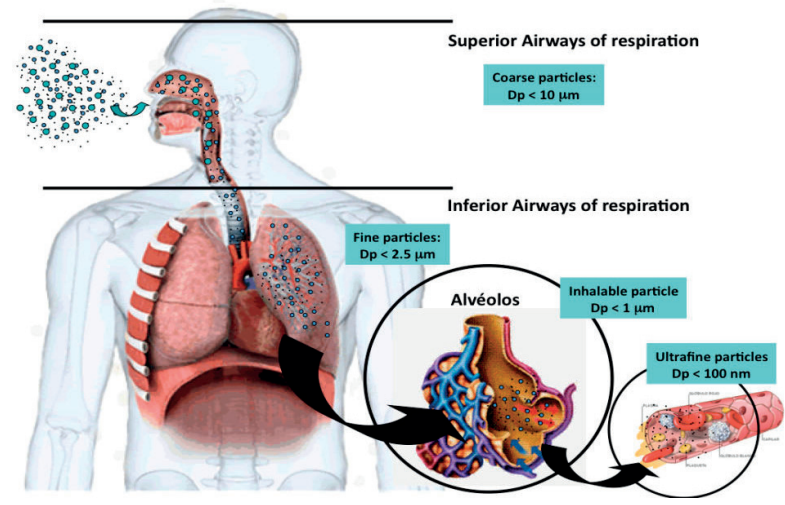

Fig. 1 The areas where particulate material is deposited in the body [6]

Behavior of particulate matters in the air and also the influence on human body is determined partly by their size. Coarse particulates can be filtered by natural human defense system in nose or they are sneezed or coughed out of body. But there are also smaller ones, the fine particles. The biggest attention is paid to $\mathrm{PM}_{10}$ (particulate matter less than 10 microns in diameter) and $\mathrm{PM}_{2.5}$ (less than 2.5 microns in diameter). Those small particles are able to get deep into the lungs and into the alveolus. The smallest ones are even able to get into the blood stream. For better imagination particulate matter $\mathrm{PM}_{10}$ is at average 7 times smaller than human hair in diameter and $\mathrm{PM}_{2.5}$ is even 28 times smaller than human hair [4 and 5].

Particulate matter emissions from biomass combustion have various sizes. Higher concentration of the particles is with the finer sizes. Particles with size $\mathrm{PM}_{10}$ make around $35 \%$ of total particle matter emission of combustion [8, 9 and 10].

\section{Separation of Particulate Matter}

In order to minimize amount of particles emitted into the ambient atmosphere various solutions are researched. Usually the appliances which produce particles are connected with filters or external separators. It is effective but it can be expensive. Sometimes this technology is more costly than the appliances itself. Therefore, solutions which could decrease particle concentration and still would not be so costly are looked for.

One of the options how to decrease particulate matter concentration is trapping particles before flying out of the combustion devices. It can be achieved by making construction changes of the combustion chamber and flue gas path.

The essential thing of every separation process, in which solid particles are separated, is to remove solid particles away from flue gas and get them into a trapping place. The trapping of particles is theoretically explained by cooperation of few together working separation processes.

\subsection{Separation Process}

The separation of solid particles has several steps. The first step, as already mentioned, is to separate the solid particles from a fluid flow into the wall of separator. In this step various principles and forces are important, for example, the force of gravity, centrifugal force, inertia force, electrostatic force, diffusive force and others. The second step is to get the solid particulate matter into the trapping place and avoid getting it back to the stream of fluid. It is also carried out in various ways. For example, a dry mechanical separator uses flow of carrier gas. The particles are carried close to the separation wall and taken away into the trapping place [11].

This type of separator is interesting because its principles can be applied in small heat sources. The scale of separation is from 3 to $30 \mu \mathrm{m}[11]$.

\section{CFD Modeling as Option of Reducing Pollution}

Simulation of various physical processes is necessary for many experiments from economic, ecological and safety point of view. Modeling together with experiments, enables a cost-effective approach not only for future biomass combustion application designs [1].

CFD program offers a possibility to solve numerically the essential physical equations as conservation of mass, energy and momentum etc. Modeling improves our understanding of the fundamental process involved in combustion appliances and may significantly reduce the "trial and error" development time needed when experiments are used for design optimization only. By combining modeling with experiments, an improved design is possible with respect to the reduction of emissions from combustion. Parametric studies can be carried out to reveal the relative influence of different combustion processes and flow variables on emission levels and energy efficiency [1].

This type of program can simulate various physical processes which can help also with a particulate matter concentration. We can simulate the flow in small combustion devices too.

To simplify the model of the particulate matter flow and reduce computational time needed, it is possible to make modeling without combustion. Some of the input parameters are given in Table 1.

Input data for simulation

Table 1

\begin{tabular}{|l|l|l|l|}
\hline Number & Input parameters & Value & Unit \\
\hline 1 & Pressure on inlet & 0 & $\mathrm{~Pa}$ \\
\hline 2 & Pressure on outlet & -12 & $\mathrm{~Pa}$ \\
\hline 3 & Temperature & 25 & ${ }^{\circ} \mathrm{C}$ \\
\hline 4 & Density & 1.185 & $\mathrm{Kg} . \mathrm{m}-3$ \\
\hline
\end{tabular}




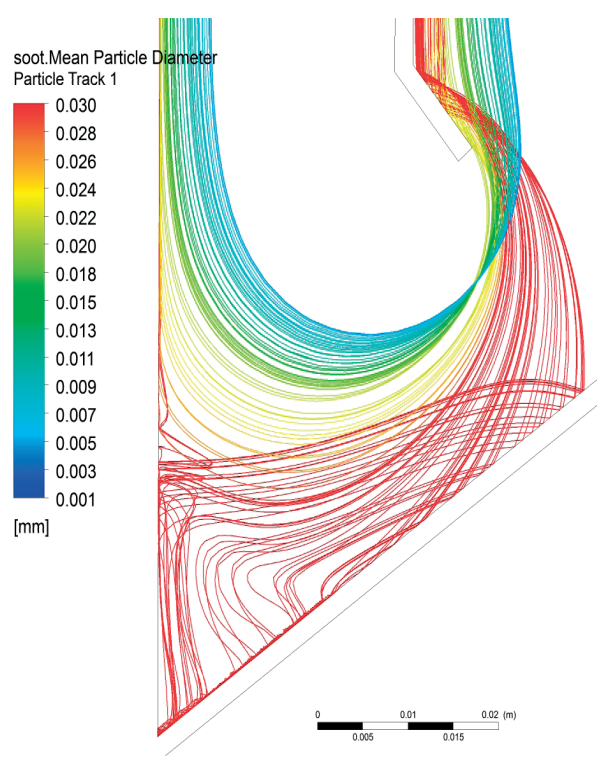

anssys

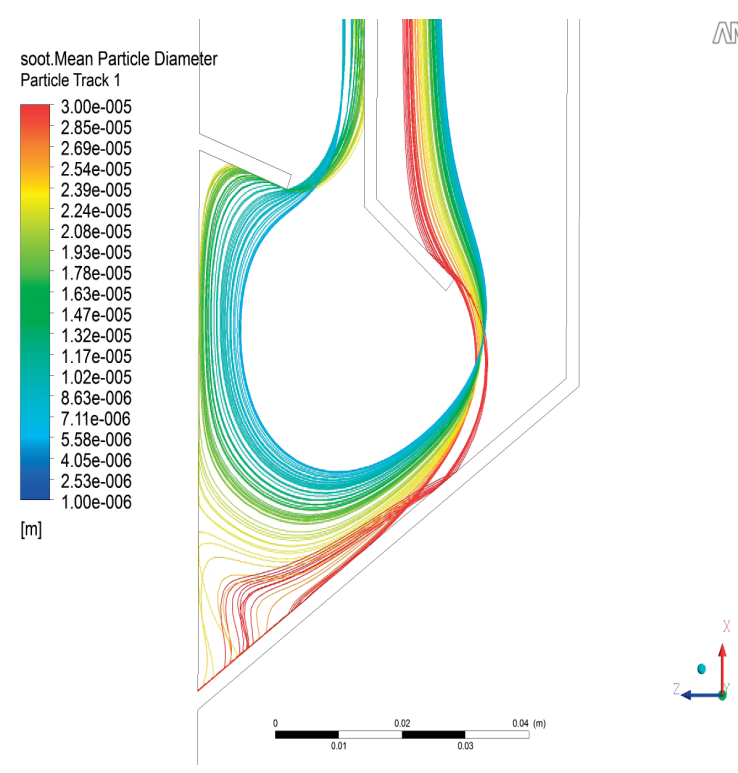

Fig. 2 Idealized flow of particles

The source of particulate matter emission with the certain amount of mass flow is given into the model. It is necessary to consider the gravity force in the model because it is important for trapping particles and, therefore, we are able to observe behavior of those solid particles in the flue gas path. It is also assumed that the process is time independent, steady; the fluid is incompressible air in the simulation [12].

Solid particles in the model are defined by Rosin-Rammler distribution in order to see various sizes of those particles. Just flow of fluid and trajectory of particle is sufficient for simplification.

In the flue gas path variable constructions can be performed. The influence of this construction on flow and on trapping of the particles can be closely observed by this program. It allows to see the effect of the construction changes on velocity, pressure, turbulence, etc. This helps to make useful changes in order to improve the construction of the small combustion devices with respect to minimizing particle emission.

A fireplace with a special tunnel placed in flue gas path was used in this work. In Fig. 2 we can see an idealized flow of particles in the trapping place in the special tunnel with two various constructions. The bigger particles are trapped at the bottom and the smaller particles are flowing away with smoke. There is possibility to trap more particles with appropriate construction changes.

\section{Experimental Verification}

Verification of the simulation results is possible to make by a gravimetric measure method, a laser measurement or other similar measurements of a particle concentration. Gravimetric method (Fig. 3) where multiple sampling is done by observance of the isokinetic conditions can be used. Samples are taken during several measurements. This method is based on determination of the mean concentration of particulate matter by manual taking of samples from time cross section of measurement and its consistent gravimetric interpretation. Representative sampling is performed by a sampling probe with a proper shape right from the gas stream [8 and 13].

Two series of measurements have to be made. One series before the construction changes, second series of the measurements after the construction changes. These two series are necessary for the comparison of values of a particulate matter concentration from the first series with those from the second series. This comparison shows whether the construction changes helped to avoid the solid particle production into the ambient air or not.

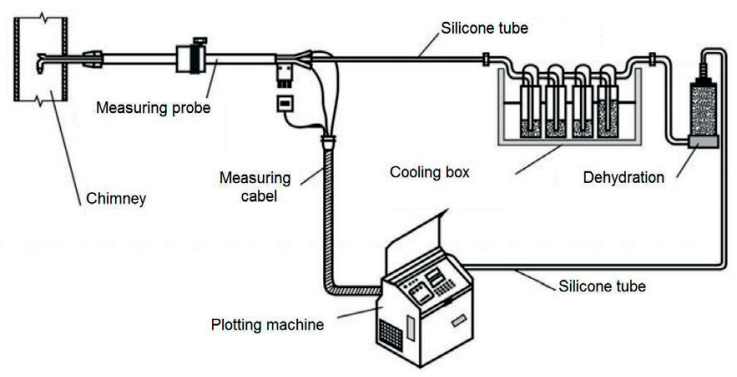

Fig. 3 Gravimetric method scheme [10]

\section{Analysis of Results}

Two various constructions were chosen for measurements. The first construction is the original one, without changes, while the second construction underwent some changes. This changed one seems to have better separation properties in the 


\begin{tabular}{|l|l|l|l|}
\hline & First series of measurements & Second series of measurements & Unit \\
\hline Average weight of wood & 2.994 & 2.952 & $\mathrm{~kg}$ \\
\hline Average concentration calculated on $13 \% \mathrm{O}_{2}$ & 56.31 & 49.63 & $\mathrm{mg} \cdot \mathrm{m}^{-3}$ \\
\hline
\end{tabular}

modeling results than the original one, therefore it was selected for comparison.

Gravimetric measurements were made on a fireplace with beech wood combustion. Isokinetic condition and other conditions for gravimetric method were followed. The conditions were the same for both series of measurements. The average values of measurements are presented in Table 2.

The average particulate matter concentration in the first series is $56.3 \mathrm{mg} / \mathrm{m}^{3}$, in the second series the average value is $49.6 \mathrm{mg} / \mathrm{m}^{3}$. The second series of measurements showed lower concentration of particulate pollution then the first ones. We can assume that it is due to construction changes which were made in compliance with the previous simulation.

\section{Conclusion}

The widespread biomass usage brings problems connected with the particulate matter production resulting from biomass combustion, especially in small domestic heat sources. Their contribution to particulate matter concentration is remarkable mainly during winter heating season. As the amount of those appliances increases, the particle pollution produced by them also increases.

Particulate matter emissions formed in heat sources impair the air quality and have harmful influence on human health; therefore, it is very important to reduce the concentration of solid and also gaseous emissions.

The use of CFD simulation in combination with experiments seems to be a good way to reduce particles emission. It not only enables to see particulate matter flow in combustion devices but also to see how particulate matter concentration can be dependent on construction changes. It can help to decrease air pollution.

\section{Acknowledgement}

This work is supported by the financial assistance of the project VEGA No. 1/1290/12.

\section{References}

[1] VAN LOO, S., KOPPEJAN, J.: The Handbook of Biomass Combustion and Co-firing, Earthscan, London: Washington, p. $442,2008$. ISBN 978-1-84407-249-1.

[2] Euractiv: Air in Europe Contains Many Harmful Substances (in Slovak), 2012, online: http://www.euractiv.sk/zivotne-prostredie/ clanok/ovzdusie-v-europe-obsahuje-vela-skodlivych-latok-020019

[3] TISSARI, J.: Fine Particle Emissions from Residential Wood Combustion, online: Doctoral dissertation, Kuopio University Publications, C. Natural and Environmental Sciences 237, 2008. p. 63. ISBN 978-951-27-1090-4 (PDF), Finland, Kuopio 2008 < http://wanda.uef.fi/uku-vaitokset/vaitokset/2008/isbn978-951-27-0975-5.pdf>

[4] ABBOT, J., STEWART, R., FLEMONG, S., STEVENSON, K., GREEN, J., COLEMAN, P.: Report to the Scottish Government. Measurement and Modelling of fine particulate emission (PM10 \& PM2.5) from wood - burning biomass boilers, Edinburg 2008, ISBN 978-0-7559-7296-8

[5] EPA United States Environmental Protection agency, Particulate matter, online : www.epa.gov/airquality/particlepollution/

[6] GUERREIRO, C., DE LEEUW, F., FOLTESCU, V., SCHILLING, J., VAN AARDENNE, J., LUKEWILLE, A., ADAMS, M.: European Environment Agency, Air quality in Europe - 2012 report, ISBN 978-92-9213-328-3

[7] EC - European commission, Air Quality Standards, 2013Environment - Air - Airquality. online: http://ec.europa.eu/environment/ air/quality/standards.htm

[8] JANDACKA, J., NOSEK, R., PAPUCIK, S., HOLUBCIK, M.: Analysis of the Particulate Matter Emission Measurement of Small Heat Sources by Various Methods (in Slovak), 30. setkani mechaniky tekutin a termomechaniky.

[9] MOLNAR, L.: Environmental Protection (in Slovak), 2011 online

[10] JANDACKA, J., MALCHO, M., MIKULIK, M.: Ecological Aspects of Substitution Fossil Fuels for Biomass (in Slovak), 2008, ISBN 978-80-969595-5-6, Jozef Bulejcik, 01001Mojs 94

[11] CERNECKY, J., NEUPAUEROVA, A., JANOSKO, I., SOLDAN, M.: Environment Engineering (in Slovak), Technicka univerzita vo Zvolene, 2010, p. 274, ISBN 978-80-228-2161-2, 2010.

[12] LENHARD, R., MALCHO, M.: Numerical Simulation Device for the Transport of Geothermal Heat with Forced Circulation of Media. Mathematical and Computer Modelling, No. 1-2, vol. 57, 2013, ISSN 0895-7177, pp. 111-125.

[13] HUZVAR, J., NOSEK, R.: Impact of Fuel Supply to Concentrations of Missions in Domestic Boiler, Power control and optimization, Proc. of fourth global conference, 2010, Kuching, [S.1.: s.n.], 2010. - ISBN 978-983-44483-32. 